\title{
The Microbiome of the Cosmopolitan Diatom Leptocylindrus Reveals Significant Spatial and Temporal Variability
}

\author{
Penelope A. Ajani*, Tim Kahlke, Nachshon Siboni, Rick Carney, Shauna A. Murray and \\ Justin R. Seymour
}

Climate Change Cluster, University of Technology Sydney, Sydney, NSW, Australia

The ecological interactions between phytoplankton and marine bacteria have important implications for the productivity and biogeochemistry of ocean ecosystems. In this study we characterized the microbial assemblages associated with multiple isolates of the ecologically important diatom Leptocylindrus using amplicon sequencing of the $16 S$ rRNA gene, to examine levels of conservation of the microbiome across closely

OPEN ACCESS

Edited by:

Tony Gutierrez,

Heriot-Watt University,

United Kingdom

Reviewed by:

Carl J. Carrano,

San Diego State University,

United States

Terry John McGenity,

University of Essex, United Kingdom

*Correspondence:

Penelope A. Ajani

Penelope.Ajani@uts.edu.au

Specialty section:

This article was submitted to

Aquatic Microbiology,

a section of the journa

Frontiers in Microbiology

Received: 28 August 2018 Accepted: 29 October 2018

Published: 15 November 2018

Citation:

Ajani PA, Kahlke T, Siboni N,

Carney R, Murray SA and

Seymour JR (2018) The Microbiome

of the Cosmopolitan Diatom Leptocylindrus Reveals Significant Spatial and Temporal Variability.

Front. Microbiol. 9:2758.

doi: 10.3389/fmicb.2018.02758 related species or strains. We also assessed if the microbiome structure of a given diatom strain was dependent on the location from which it was isolated and if the microbiome of cultured isolates significantly changed overtime from the seawater in which they were isolated. The bacterial assemblages from 36 strains belonging to three species (Leptocylindrus danicus, Leptocylindrus convexus, and Leptocylindrus aporus) isolated from six locations spanning $>1000 \mathrm{~km}$ of south east Australian coastline over 1 year, were dominated by the Rhodobacteraceae ( 60\%) and the Flavobacteriaceae ( 10\%). Across all strains, only one 'core OTU' (Roseovarius sp.) was identified across all samples. We observed no significant differences in bacterial community composition between diatom species. Significant differences in microbiome structure were, however, observed between diatom strains collected at different sampling times and from differing locations, albeit these two factors were coupled. Moreover, while bacterial communities under domestication varied from the seawater in which they were isolated, they remained specific to the location/month of origin, i.e., different regions and time points harbored distinct bacterial communities. Our study delivers new knowledge in relation to diatom-bacterial associations, revealing that the location/time from which a diatom is isolated plays an important role in shaping its microbiome.

Keywords: diatom, bacteria, phycosphere, network analysis, Roseovarius

\section{INTRODUCTION}

The interactions between phytoplankton and bacteria are among the most significant ecological associations in the global ocean (Amin et al., 2012). While regularly considered in isolation, the ecology and physiology of these important functional groups of aquatic microorganisms are often closely coupled with interactions spanning mutualism, commensalism, parasitism, and competition 
(Seymour et al., 2017 and references therein). These dynamic relationships are often complex and multifaceted, with the, sometimes reciprocal, exchange of metabolites and info-chemicals regulating a suite of important ecosystemlevel processes including nutrient transformation, primary production, toxin biosynthesis, and biogeochemical cycling (Amin et al., 2012, 2015; Durham et al., 2015). In addition to the recognition of the importance of phytoplankton-bacterial interactions within oceanographic and aquatic ecological contexts, efforts to disentangle the relationship between bacteri,a and phytoplankton is also gaining momentum in the field of biotechnology. The optimization of microalgal cultivation (Cho et al., 2015), the augmentation of high value bio-products (Richter et al., 2018), and their use in natural remediation processes (Gutierrez et al., 2013) are all examples where greater insights into microbial associations will benefit (Ramanan et al., 2016 and references therein).

Many species of marine phytoplankton exhibit strong ecological links with specific members of the Proteobacteria and Bacteriodetes, including species of Sulfitobacter, Roseobacter, Alteromonas, and Flavobacterium (Amin et al., 2012; Buchan et al., 2014). These bacterial associates have been demonstrated to modify the growth, behavior and physiology of the microalgal host (Sison-Mangus et al., 2014; Segev et al., 2016; Bolch et al., 2017; van Tol et al., 2017), and to become abundant during phytoplankton blooms, for which they may play a role in governing bloom dynamics (Buchan et al., 2014; Bunse et al., 2016; Hattenrath-Lehmann and Gobler, 2017; Needham et al., 2017; Song, 2017).

It is widely anticipated that many of these specific phytoplankton - bacterial interactions are based on the active exchange of signaling molecules and/or nutrients (Green et al., 2015; Seymour et al., 2017). While it was traditionally thought that these interactions would be simply based on the provision of the organic products of photosynthesis to bacteria and perhaps remineralized nutrients to phytoplankton (Azam and Ammerman, 1984; Legendre and Rassoulzadegan, 1995), it is becoming evident that the chemical exchanges between phytoplankton and bacteria are much more diverse, specialized, and complex. For instance, tryptophan/indole-3-acetic acid (IAA), a common and important hormone for plant growth and development, has been shown to be received by the diatom Pseudo-nitzschia multiseries from the bacteria Sulfitobacter, which subsequently promotes diatom cell division (Amin et al., 2015). Growth metabolites exuded from the diatom Thalassiosira pseudonana have been putatively linked to the growth of the bacteria Ruegeria pomeroyi (Durham et al., 2017). Furthermore, the bacterium Mesorhizobium loti has also been observed to supply vitamin B12 (cobalamin) to the freshwater green alga Lobomonas, which receives photosynthate from the phytoplankton cell in return (Grant et al., 2014).

Among the most widely studied phytoplankton-bacterial interactions are those between diatoms and bacteria. Diatoms are one of the most ecologically important phytoplankton groups in the global ocean (Malviya et al., 2016), carrying out 20\% of the Earth's photosynthesis (Armbrust, 2009) and dominating phytoplankton biomass in many coastal regions across the global ocean (Fawcett and Ward, 2011; Huang et al., 2011; Morales and Anabalon, 2012). The bacteria associated with diatoms often belong to distinct bacterial phylotypes (Alpha-, Beta,- and Gammaproteobacteria and Bacteriodetes) made up of a relatively few genera, such as Roseobacter, Sulfitobacter, and Flavobacterium (Amin et al., 2012) and their presence is often linked to specific positive and negative interactions with diatom cells. In return for diatom derived dissolved organic carbon, bacteria from these groups have been shown to provide diatom cells with vitamin $\mathrm{B}_{12}$, soluble iron (via specialized siderophores), and nitrogen (via certain nitrogen-fixing cyanobacteria) (Croft et al., 2005; Foster et al., 2011; Amin et al., 2012). In contrast, some bacteria from these groups produce algicides which may kill diatoms (Lau et al., 2007), an in turn some diatoms can produce antibacterial compounds as a defense feature (Desbois et al., 2009).

Most of our current knowledge of the interactions between diatoms and bacteria, however, is derived from examining cultured, model systems, which have focused on a limited number of algal species or strains, usually sourced from longterm culture collections (Amin et al., 2015; Moejes et al., 2017). Behringer et al., 2018 demonstrated that the bacterial communities associated with the diatom species Nitzschia longissima (three strains) and Asterionellopsis glacialis (four strains) displayed strong conservation across strains from the same species (conserved at the genus level), and that cultivation over time ( $>1$ year) resulted in only small changes to the bacterial composition.

The genus Leptocylindrus is one of the most numerically dominant diatoms in the ocean (Malviya et al., 2016) and is a major component of the spring bloom period in southeastern Australia (Ajani et al., 2016b). With its ease of microscopic identification, single cell isolation and successful growth in culture, species belonging to this genus are ideal candidates for the examination of phytoplankton-bacterial interactions. To investigate the co-existence of natural communities of bacteria and Leptocylindrus, we addressed three questions: Do bacterial communities associated with closely related Leptocylindrus species differ between and within species? Does the bacterial community associated with Leptocylindrus significantly change over time (months) from the original seawater from which it was isolated? Is the microbiome of each diatom strain predetermined by its collection time or location? By characterizing the bacteria that live in association with marine phytoplankton, we may begin to understand the function of a host organism's microbiome, and its interaction within this microenvironment.

\section{MATERIALS AND METHODS}

\section{Phytoplankton Collection, Culture Maintenance, and Species Characterization}

Non-axenic monoclonal batch cultures of Leptocylindrus were established by single cell isolation using drawn out Pasteur pipettes (micropipettes) from net samples (20- $\mu \mathrm{m}$ mesh size) collected from six locations along the southeastern Australian 
coastline from December 2015 to October 2016. Sampling sites included Coffs Harbor $\left(30.3^{\circ} \mathrm{S}, 153.1^{\circ} \mathrm{E}\right)$, Forster $\left(32.2^{\circ} \mathrm{S}\right.$, $\left.152.5^{\circ} \mathrm{E}\right)$, Coogee $\left(33.9^{\circ} \mathrm{S}, 51.2^{\circ} \mathrm{E}\right)$, Clovelly $\left(33.9^{\circ} \mathrm{S}, 151.26^{\circ} \mathrm{E}\right)$, Maroubra $\left(33.9^{\circ} \mathrm{S}, 151.24^{\circ} \mathrm{E}\right)$ and Twofold Bay $\left(37.08^{\circ} \mathrm{S}, 149.9^{\circ} \mathrm{E}\right)$ from north to south (Figure 1). The locations of Coogee, Clovelly and Maroubra are all located within the urban surrounds of the city of Sydney.

Leptocylindrus isolates were grown in 24-well plates containing autoclaved F/2 media (Guillard, 1975) and monitored using light microscopy. Once established, each strain was transferred to $50 \mathrm{~mL}$ culture flasks and maintained in a constant temperature incubator at $16-18^{\circ} \mathrm{C}$ under a white light flux of 60-100 $\mu$ mol photon $\mathrm{m}^{-2} \mathrm{~s}^{-1}$ and a 12-h light (L):12-h dark (D) cycle. One $\mathrm{mL}$ of culture from each strain was transferred into fresh media every 2 weeks to maintain healthy and exponentially growing cultures.

Species identification was confirmed by both morphological examination, using transmission electron microscopy, and sequencing of the nuclear-encoded partial ITS15.8S-ITS2 region of rDNA using the primers ITS-for $\left(5^{\prime}\right.$-ATATGCTTAAATTCAGCGGGT- $\left.{ }^{\prime}\right)$ and ITS-rev $\left(5^{\prime}\right.$ TTTCCGTAGCTGAACCTGCGG-3') (see Ajani et al., 2016a for further details). At approximately the same time as diatom strain collection, bulk water samples $(3 \times 5 \mathrm{~L})$ were collected from two near shore (1 $\mathrm{m}$ depth) sites at Maroubra Beach, $\left(33.9^{\circ} \mathrm{S}\right.$, $151.24^{\circ} \mathrm{E}$ ). From each of these bulk samples, $2.5 \mathrm{~L}$ was filtered through a $0.22 \mu \mathrm{m}$ pore size membrane filter (Millipore) using a peristaltic pump. Filters were stored at $-80^{\circ} \mathrm{C}$ prior to DNA extraction.

\section{DNA Extraction and 16S RNA Sequencing}

To examine variability in the Leptocylindrus microbiome across strains, $5 \mathrm{~mL}$ of each strain was transferred to a $50 \mathrm{~mL}$ culture flask ( $\times 3$ replicates) at the final culture transfer and maintained as described above. For all strains, this occurred between 6 and 16 months after initial cell isolation (Supplementary Table 1). On day $18(\sim$ stationary phase $)$ each replicate strain was harvested by centrifugation (2300 RCF for $5 \mathrm{~min}$ ), and total DNA extracted from the pellet using a DNeasy ${ }^{\circledR}$ PowerSoil $^{\circledR}$ Kit (Qiagen) as per manufacturer's protocol. Bulk water samples were filtered through $0.22 \mu \mathrm{m}$ pore-size membrane filters (Millipore) using a peristaltic pump and stored at $-80^{\circ} \mathrm{C}$ prior to DNA extraction. For water samples, DNA extraction was performed using the Powerwater DNA isolation Kit (Qiagen) in accordance with the manufacturer's instructions. DNA quantity and quality was examined spectroscopically with a Nanodrop (ND-1000, Thermo Scientific, Woltham, MA, United States).

The V1-V3 variable region of the bacterial 16S rRNA gene was amplified by PCR, using the primers $27 \mathrm{~F}$ (AGAGTTTGATCMTGGCTCAG, Lane, 1991) and 519R (GWATTACCGCGGCKGCTG, Turner et al., 1999). 16S rRNA amplicon sequencing was subsequently performed on the Illumina MiSeq platform (Molecular Research LP; Shallowater, TX, United States) following the manufacturer's guidelines.
Raw data files in FASTQ format were deposited in NCBI Sequence Read Archive (SRA), with the study accession numbers PRJNA488135 and SRP143624 (diatom and bulk water samples, respectively).

\section{Sequence Data Processing and Bacterial Community Analyses}

Bacterial 16S rRNA sequencing data was processed using a customized bioinformatic workflow as described in Kahlke (2018); Ampli-tools (Version 1.0); Zenodo]. Briefly, paired-end $16 \mathrm{~S}$ sequences were joined using FLASH (Magoc and Salzberg, 2011) and subsequently trimmed using Mothur (Schloss et al., 2009) (maxhomop $=6$, maxambig $=0$, minlength $=434$, maxlength $=489)$. The resulting fragments were clustered into operational taxonomic units (OTUs) at $97 \%$ identity and chimeric sequences were identified using vsearch (Rognes et al., 2016) and the Silva (v128) database. Taxonomy was assigned using QIIME (Caporaso et al., 2010) and BLAST against the Silva v128 database. Sequences were rarefied to 15,000 fragments to limit the effects of uneven sequencing depth.

Bacterial community patterns were examined for differences among diatom strains and species, date of isolation (month) and sampling location. Alpha diversity parameters (Shannon Diversity Index, Chao1, and the number of observed OTUs per sample) of the rarefied sequences were calculated in QIIME (Caporaso et al., 2010). These were compared using Kruskal-Wallis (non-parametric one-way analysis of variance by ranks, $p<0.05$ ) in STATISTICA v13.0 (StatSoft, Tulsa, OK, United States) to test for differences between time of isolation (months 1, 2, 10, and 12) and between sampling locations. A Jackknife (Qiime v1.9) comparison of the weighted rarefied data was then used to examine to what extent the bacterial community differed between the original seawater at the time of collection.

Non-parametric (multivariate) analyses were also undertaken to compare Leptocylindrus microbiomes between strains (and replicates), species, months and sampling locations. Using the relative abundance data (after a log $[\mathrm{x}+1]$ transformation to 'down weight' the most abundant bacterial OTUs) multidimensional scaling was applied to provide an ordination of the data using the Bray-Curtis similarity measure using PRIMER-E v6 (Clarke and Gorley, 2006). Analysis of similarity (ANOSIM) was then used to investigate differences, and where significant, the similarity percentages procedure (SIMPER) was used to identify the OTUs most responsible for these discriminations (Clarke and Warwick, 2001).

\section{Leptocylindrus Core Microbiome}

To identify OTUs of putative ecological importance to Leptocylindrus, the core microbiome was determined for: (a) all strains to identify the OTUs that were universally associated with the three Leptocylindrus species, and (b) strains taken from the same location to investigate the effect of location on core microbiome structure. An OTU was defined as a member of the core microbiome if it was present in at least two out of 


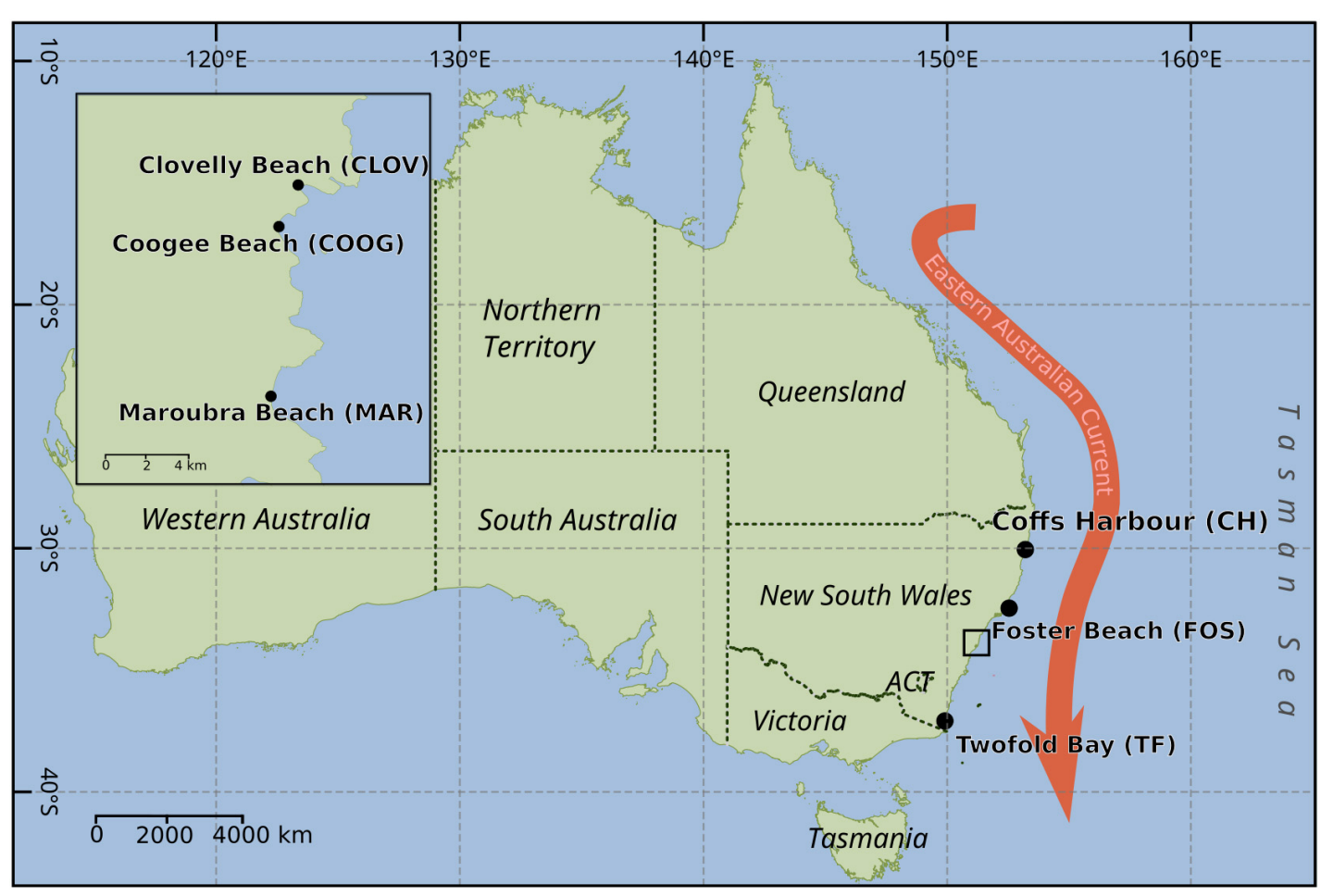

FIGURE 1 | Map of Australia, showing the sampling locations for the isolation of the diatoms Leptocylindrus as shown by black dots. Black box indicates sampling locations within the urbanized area of Sydney. Red arrow indicated the dominant western boundary current along the southeast of Australia - the East Australian current.

three replicates for each sample type (i.e., allowing for one replicate outlier per group). Similarly, for the location-specific core microbiome, an OTU was considered a member of the core microbiome if it was present in all replicates of all strains taken at the same location. This more stringent cut off was chosen due to a lower number of strains and the assumption that geographically closer sampling sites have a higher chance of sharing common OTUs.

\section{Bipartite Network Analysis}

To further compare the composition of bacterial OTU assemblages across locations/months, a bipartite network was created using 16S rRNA amplicon data. The python command make_bipartite_network.py part of QIIME v1.9 was used for this method as previously described by Muegge et al. (2011) and Gibbons et al. (2013). This produced a dataset consisting of two node types: strains grouped by location/month of isolation and the abundance of bacterial OTUs, that is, the number of sequence reads detected for each OTU at each respective location/month. A bipartite network graph was produced from this new dataset by first pooling strain replicates, and then using the attribute circle layout feature in Cytoscape 3.6.0 (Shannon et al., 2003). This allowed the bacterial OTUs that were unique to only one location or month to be distinguished from those that were common across two or more location or months.

\section{RESULTS}

\section{Strain Characterization}

A total of 36 strains of the diatom genus Leptocylindrus were collected from six locations spanning $1069 \mathrm{~km}$ of coastline from December 2015 to October 2016 ( $<1$ year). Using the nuclearencoded partial ITS1-5.8S-ITS2 region of rDNA, the isolated strains were found to span three species, namely: Leptocylindrus danicus, Leptocylindrus convexus, and Leptocylindrus aporus, with 31,4 and 1 strains of each species established, respectively (Supplementary Table 1).

A total of 107 samples $(3 \times 36$ strains; with the exception of strain FOS180216-21, for which only 2 of 3 replicates yielded enough DNA for downstream processing) were analyzed for their bacterial community composition. Comparative sequence analysis of the $16 \mathrm{~S}$ rRNA gene libraries revealed the total number of raw reads across all replicates ranged from 91,360 to 214,451 reads and from 23,519 to 173,004 reads after quality filtering (Supplementary Table 1). Analysis of the normalized (15,000 rarefaction) sequences from replicates revealed a total of 1956 individual OTUs across all samples.

\section{Leptocylindrus Strain Comparisons}

The Shannon Diversity Index for the microbiome associated with each strain ranged from 1.97 (L. danicus from Twofold Bay, strain TF251016-1) to 4.83 (L. danicus from Coffs Harbor, strain CH230116-7). Using the Chaol estimator, the lowest diversity 
was again within the L. danicus strain isolated from Twofold Bay (strain TF251016-5), whilst the greatest species richness was observed in L. aporus from Coogee (strain COOG100215-7). The greatest overall number of rarefied OTUs (289) was recorded from a strain of $L$. danicus from Forster (strain FOS180216-2), whilst the lowest (66) was observed from $L$. danicus isolated from Twofold Bay (TF251016-5).

Significant differences in bacterial diversity were observed between time of strain isolation (species pooled) for all diversity indices measured (eg., Shannon $p<0.001$ ) and similarly, when only L. danicus strains were examined $(p<0.001)$. When strains were pooled for species and months, a significant difference between location of strain isolation was also observed $(p<0.001)$ and was similarly observed when only $L$. danicus strains were examined ( $p=0.001$ ) (Supplementary Tables 2, 3). Using the Jackknife resampling technique, the bacterial community in the seawater around the time of collection clearly discriminated from all other cultured strains (Figure 2).

Of all classified OTUs, $81.8 \%$ were Proteobacteria and $17.8 \%$ Bacteroidetes, with very minor contributions from the Actinobacteria, Cyanobacteria, Planctomycetes and Verrucomicrobia (total 0.4\%) (Supplementary Table 4 and Figure 3A). At the family level, the most commonly observed family were the Rhodobacteraceae $(60.6 \%)$, followed by the Flavobacteriaceae (10.4\%), Halieaceae (7.3\%), Cryomorphaceae (6.7\%), Alteromonadaceae (3.9\%), Erythrobacteraceae (2\%), Pseudoalteromonadaceae (2\%), and the Sphingomonadaceae (1.9\%) (Figure 3B). All other contributions at this taxonomic level comprised $<1 \%$ of the community (Figure 3B). Both the most frequently occurring (present in 106/107 replicate samples), and the most relative abundant OTU (18.5\%), across all strains was an OTU (7767), classified as an uncultured Roseovarius sp from within the Rhodobacteraceae (Supplementary Table 4 and Figure 3A).

No significant differences in diatom microbiome structure were apparent between replicates of a given strain or between species ( $L$. danicus, $L$. convexus, $\mathrm{R}$ statistic $=-0.079, p=0.844$; L. danicus, $L$. aporus $R=-0.177, p=0.864 ; L$ convexus, L. aporus $R=0.161, p=0.119$ ) (Figure 4A). However, consistent with the patterns in alpha-diversity, significant

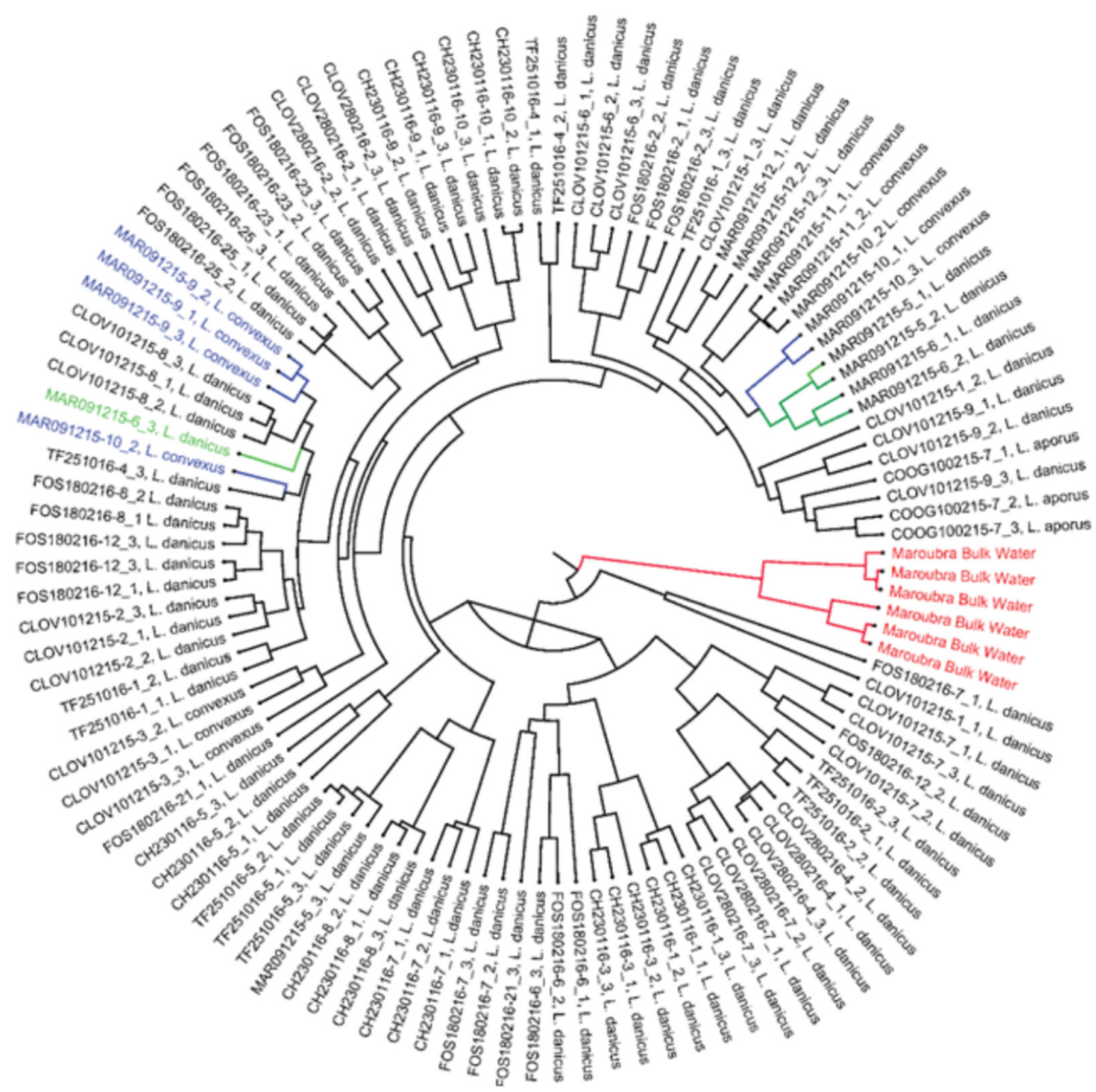

FIGURE 2 | Jack knife phylogeny based on the weighted rarefied data shows Maroubra bulk water samples (shown in red) clearly separated from other bacterial communities associated with the diatom Leptocylindrus isolated from the same location. Green: bacterial communities associated with Leptocylindrus danicus; blue: bacterial communities associated with Leptocylindrus convexus. 

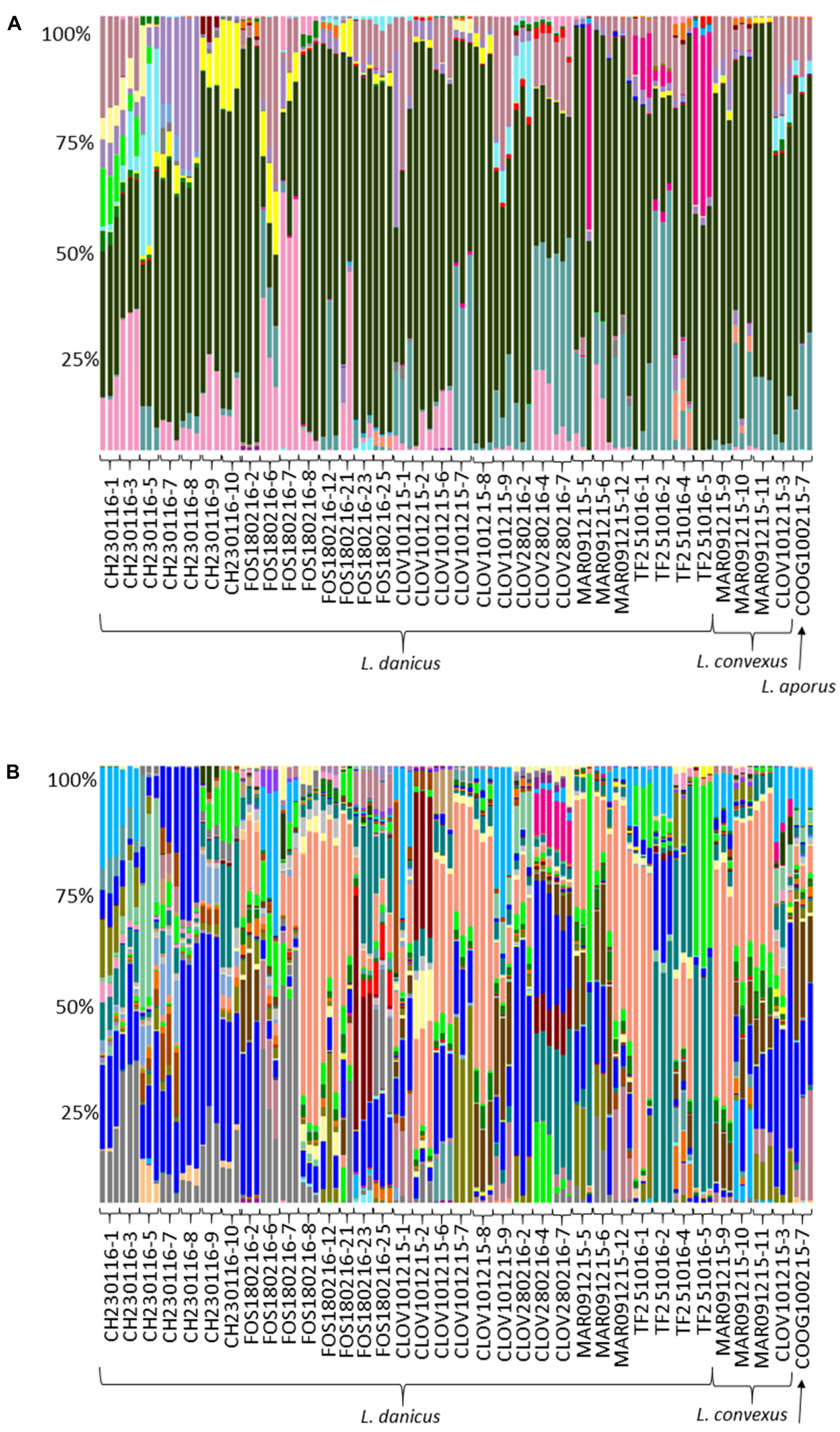

L. aporus

FIGURE 3 | Comparative sequence analysis of normalized (15000 rarefaction) 16 S ribosomal RNA (rRNA) gene libraries from all diatom strains. Each strain has three replicates with the exception of strain FOS180216-21, for which only 2 of 3 replicates yielded enough DNA for downstream processing. (A) Relative percent abundance at OTU level; 58\% were made up of Roseovarius 18\% (coral); Rhodobacteraceae; Ambiguous taxa 17.1\% (bright blue); Rhodobacteraceae, uncultured sp. 7\% (aqua); Owenweeksia 5.5\% (gray); Haliea 5\% (light blue); Donghicola 4.6\% (brown); and (B) relative percent abundance at family level; 95\% of all sequences were made up of eight families Rhodobacteraceae 60.6\% (black); Flavobacteriaceae 10.4\% (turquoise); Halieaceae 7.3\% (dark pink); Cryomorphaceae 6.7\% (pale pink); Alteromonadaceae 3.9\% (purple); Erythrobacteraceae 2\% (yellow); Pseudoalteromonadaceae 2\% (bright pink); and Sphingomonadaceae 1.9\% (light blue). 
differences were observed between the microbiomes of Leptocylindrus strains collected across different sampling months (global $R=0.635, p=0.001$ ) (Figure 4B). Significant spatial variability was also seen among strains collected from differing locations, when species and sampling times were pooled (global $R=0.573, p=0.001$ ) (Figure 4C), with the microbiomes of Leptocylindrus strains collected from Sydney urban sites (Clovelly, Maroubra, $R=0.018$, $p=0.3$; Clovelly, Coogee $R=-0.22, p=0.95$, Maroubra, Coogee, $R=0.431, p=0.018$ ) clustering together and clearly discriminated from those strains collected from the northernmost and southern-most sites at Coffs Harbor and Twofold Bay (Figure 4D). When the analysis was repeated using only L. danicus strains, the same pattern was observed (data not presented). Pairwise SIMPER analyses revealed between 4 to 8 bacterial OTUs explained $>5 \%$ of the cumulative contribution to dissimilarity among the microbiome of Leptocylindrus strains collected at differing sampling locations (Sydney sites combined), with OTUs classified as Rhodobacteraceae (Roseovarius and Donghicola) more abundant in Sydney compared to strains collected from other locations, and OTUs classified as Cryomorphaceae (Owenweeksia) more abundant in Leptocylindrus strains from Coffs Harbor compared to those isolated from other locations (Supplementary Table 5).

\section{Leptocylindrus Core Microbiome}

To understand the OTUs of putative ecological importance to Leptocylindrus, we determined the "core microbiome" across all strains cultivated. The only core OTU present across all strains/replicates was OTU 7767, Roseovarius sp., which was also the most abundant OTU across all strains (see above). When the core microbiome was calculated according to location of strain isolation, eleven core OTUs were identified at Coffs Harbor (73\% belonging to the family Rhodobacteraceae); 4 at Forster (all Rhodobacteraceae, including one Roseovarius); 4 at Clovelly (all Rhodobacteraceae, including two Roseovarius); 156 at Coogee (77\% Rhodobacteraceae); 10 at Maroubra (all Rhodobacteraceae, including several Pseudoroseovarius and one Roseovarius OTUs); and 3 at Twofold Bay (all Rhodobacteraceae, including one Roseovarius and one Pseudoroseovarius) (Supplementary Table 6). In addition to the most abundant bacterium observed across all strains (Rhodobacteraceae, Roseovarius sp. uncultured bacterium OTU 7767, see above), another unidentified Rhodobacteraceae (OTU 9240) was present in the core microbiome of strains from all locations with the exception of Coffs Harbor (Supplementary Table 6). Other OTUs, Rhodobacteraceae Shimia (OTU 10067); Rhodobacteraceae, Pseudoroseovarius, uncultured alpha proteobacteria (OTUs 10098, 10103, and 10702); and unidentified Rhodobacteraceae (OTU 10977), were only observed in the core microbiomes

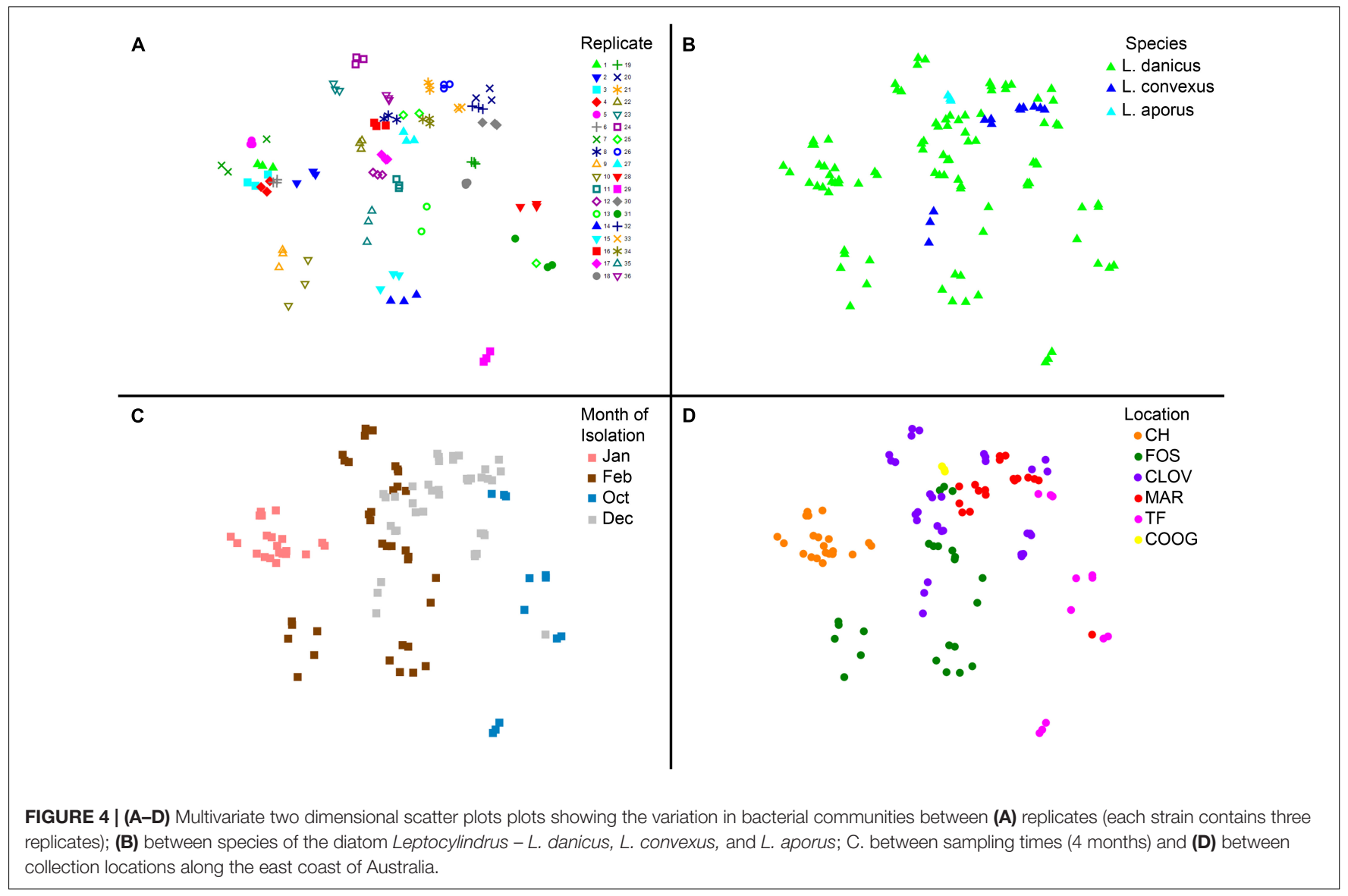


of strains from Coogee and Maroubra (Supplementary Table 6).

\section{Bipartite Network Analysis}

Bipartite analysis of the strain by location/month of isolation (7) and the abundance of bacterial OTUs (total OTUs identified 1956) identified 1,055 OTUs that were common across $>2$ location/month(s) nodes, while 902 OTUs were unique to only one location/month node (Figure 5A). The number of unique OTUs for each location/month node ranged from 15 (Coogee, February) to 305 (Forster, February), belonging to six major phyla: Actinobacteria, Bacteroidetes, Cyanobacteria, Planktomycetes, Verrucomicrobia, and Proteobacteria (Figure 5B).

\section{DISCUSSION}

Identifying the key bacteria associated with ecologically significant diatoms is a vital precursor to understanding the intricate relationships between these two microbial groups in the global ocean. While previous algal-bacterial studies have examined a limited number of model organisms from long term laboratory culture collections, our study examines $16 \mathrm{~S}$ rRNA sequences obtained from 36 clonal isolates spanning 3 species of the diatom Leptocylindrus, collected over a 1-year period and from six locations spanning $1000 \mathrm{~km}$ of the coastline. Data collected over the past 50 years from a long-term coastal monitoring station (Port Hacking - at a depth $100 \mathrm{~m}$ ) has revealed that Leptocylindrus is one of the most abundant genera observed in these coastal waters, dominating the spring and summer diatom bloom periods (Ajani et al., 2014a,b). The ecological importance of Leptocylindrus has also been recognized by the recent Tara Ocean expeditions, reporting this genus to be one of the five most abundant diatoms globally (Malviya et al., 2016). Moreover, Leptocylindrus is reported as one of the least diverse genera, making it an ideal candidate to investigate the mechanisms underlying bacterial-diatom interactions.

\section{Leptocylindrus Strain and Species Comparisons}

Our results indicate that the bacterial communities associated with different strains of Leptocylindrus recently isolated from natural environments were generally conserved across three species, namely $L$. danicus, $L$. convexus, and $L$. aporus. In all Leptocylindrus strains the bacterial community was dominated by the Proteobacteria $(\sim 80 \%)$ and the Bacteroidetes $(\sim 20 \%)$, while at the family level the most important bacterial groups were the Rhodobacteraceae $(\sim 60 \%)$ and Flavobacteriaceae $(\sim 10 \%)$. This is consistent with previous studies that have demonstrated that these are the dominant heterotrophic bacterial groups associated with diatoms (Amin et al., 2012 and references therein) and other phytoplankton (Buchan et al., 2014).

More specifically, the most abundant bacterial group within Leptocylindrus microbiomes, the Roseobacter, are one of the most pervasive microbial genera interacting with phytoplankton in the marine ecosystem (Moran et al., 2003; Ramanan et al., 2016). The second dominant group, the Flavobacteria, are abundant in coastal upwelling regions from temperate to polar oceans and are also widely recognized as phytoplankton-associates (Buchan et al., 2014). Of the $10-20 \%$ of Bacteroidetes that are present in the open ocean bacterial community, the Flavobacteria are the most common. They are also commonly reported during phytoplankton blooms, where distinct phylotype succession patterns have been observed (Buchan et al., 2014 and references therein). Thought to be more opportunistic than the Roseobacter clade, this group has been reported to more frequently be particle/diatom-attached rather than free-living microbes (Grossart et al., 2005). It is hypothesized that this niche separation is one way in which competing species of bacteria (Rosebacter and Flavobacter) can partition their influence on the ecophysiology of diatoms and successfully coexist in the marine environment (Teeling et al., 2016).

While our study showed bacterial assemblages were generally conserved across closely related species, differing diatom genera eg., Ditylum, Thalassiosira, Astrionella, Chaetoceros, Leptocylindrus and Coscinodiscus, have been shown to develop and maintain distinct bacterial satellite assemblages even when 'challenged' with alternate bacterial assemblages (Schafer et al., 2002). A recent study by Behringer et al. (2018) also supported this conservation of bacterial communities at the genus level, with strains of the diatoms A. glacialis and N. longissima maintaining stable microbial communities across strains and highly conserved microbiomes at the phytoplankton genus level. In the same way, the bacterial communities associated with strains of Pseudonitzschia spanning six different species were found to be similar, with significant microbiome differences only reported between toxigenic and non-toxigenic species (Guannel et al., 2011). Whilst both the toxic species (P. multiseries) and the non-toxic species ( $P$. delicatissima) hosted common bacterial members (eg., Roseobacter, Gammaproteobacteria and Flavobacteria), the bacterial community of the toxigenic species (P. multiseries) was far less abundant and diverse than the non-toxigenic species. Furthermore, when two axenic marine diatoms (Thalassiosira rotula and Skeletonema costatum) were inoculated with natural bacterial assemblages, the resultant free-living and attached bacteria differed both between the diatom species and between the growth stages within a single species (Grossart et al., 2005). Of the two distinct bacterial communities that evolved over time under cultivation, members of the Roseobacter group dominated the free-living community while the Flavobacteria-Sphingobacteria were the main representatives in the diatom-associated assemblage.

\section{Leptocylindrus Spatial and Temporal Comparisons}

Bacterial communities co-existing with certain species of diatoms are generally dominated by a distinct consortium of bacteria that are conserved over geographical locations and time under laboratory cultivation (Guannel et al., 2011). Amin et al. (2012) reported consistent associations between specific clades of bacteria associated with strains of Pseudo-nitzschia isolated from the Atlantic Ocean and the North Pacific Ocean. Whilst these conserved consortia may exist at the genus level or above, our data suggests however, that at the operational taxonomic 


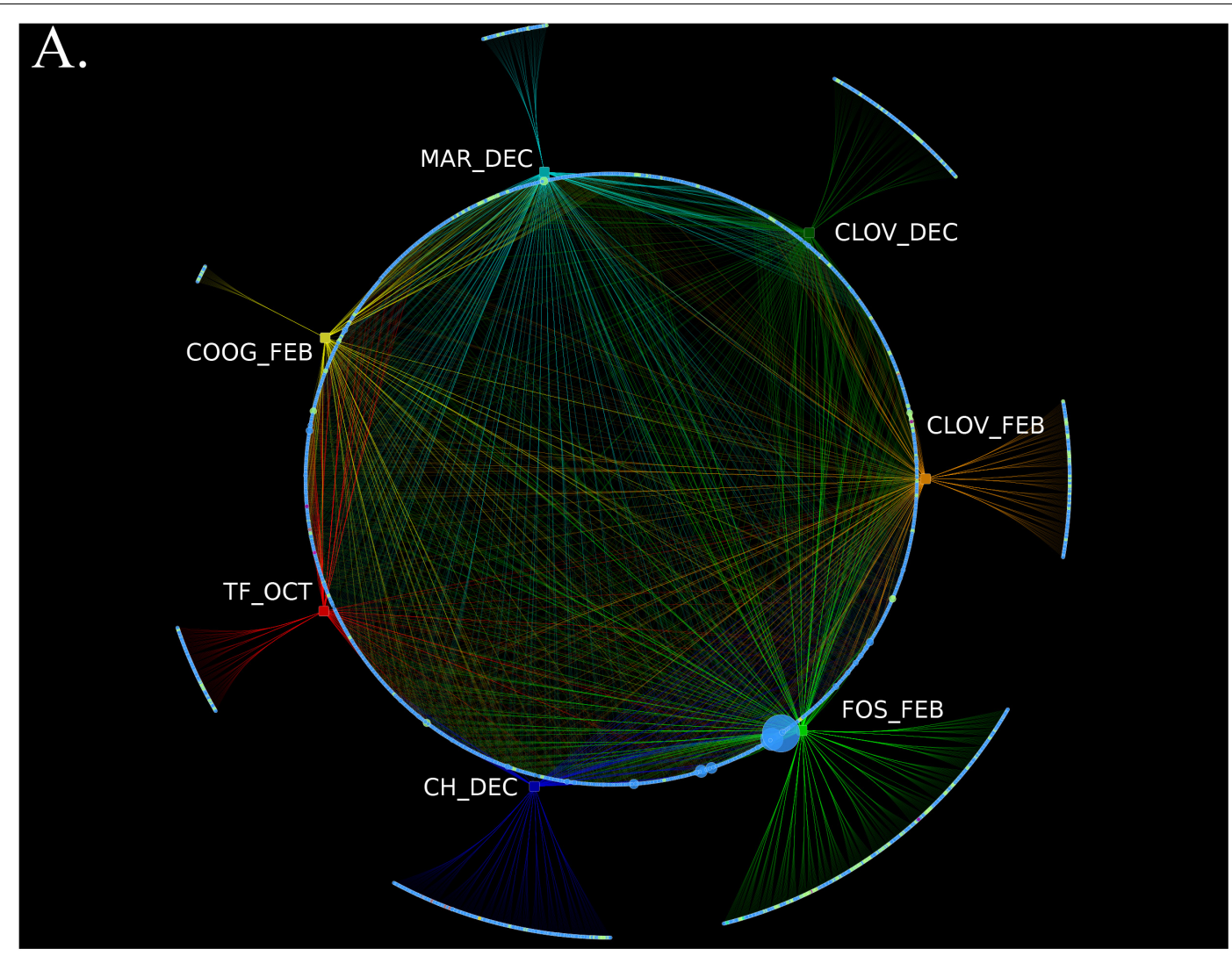

B.

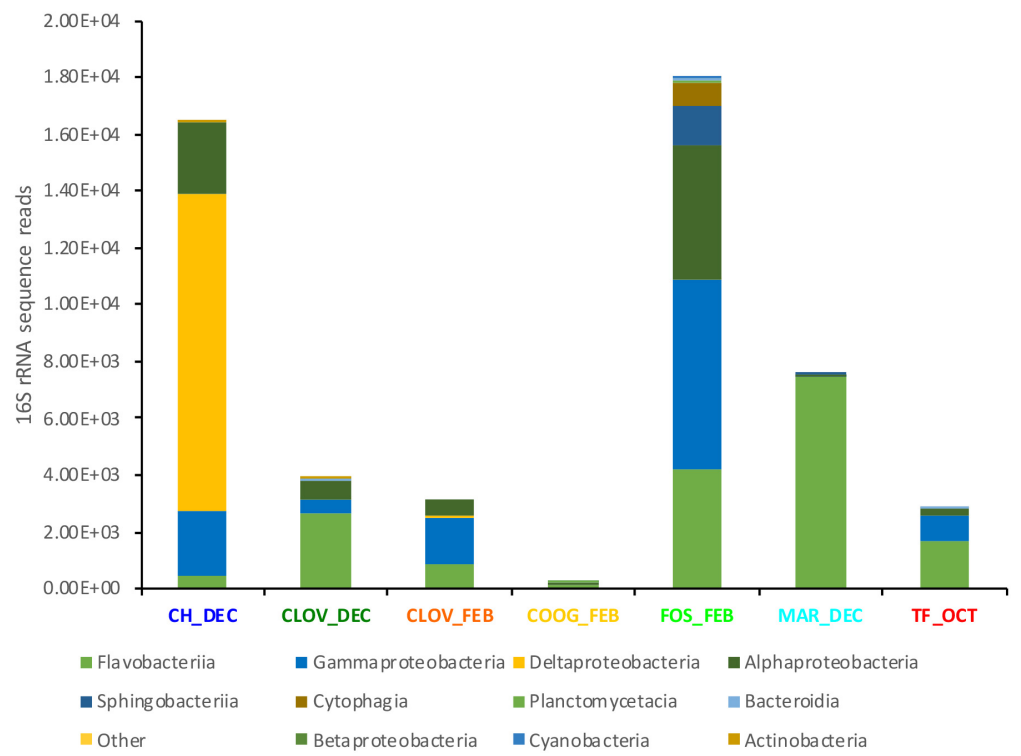

FIGURE 5 | (A,B) A Phytoplankton isolates harbor different bacterial consortium depending on the location and time of sampling from the environment. (A) Bipartite analysis of 7 location/timepoints (rectangles) and 1957 bacterial OTU nodes (circles), yielded 4605 edges (lines), each representing the sum number of 165 rRNA sequence reads for each bacterial OTU at their respective location/timepoint. Nodes representing bacterial OTUs were colored by phyla assignment; Actinobacteria (yellow), Bacteroidetes (light green), Cyanobacteria (teal), Planktomycetes (purple), Verrucomicrobia (violet), and Proteobacteria (blue). Edge colors were set to match the color of their respective location/time point nodes. Bipartite analysis revealed 1,055 "common" bacterial OTUs that were connected via an edge with $>2$ location/time point nodes. Whereas, 902 bacterial OTUs were unique to only one location/timepoint, including CH_DEC (188), CLOVE_DEC (131), CLOV_FEB (131), COOG_FEB (15), FOS_FEB (305), MAR_DEC (55), and TF_OCT (77). (B) Stacked bar plots showing the phylogenetic composition and overall abundance of unique OTUs at each location/time point. 
unit (OTU) level, significant spatial and temporal variability is retained under cultivation across diatom microbiomes. Specifically, we observed significant dissimilarity in the composition of the Leptocylindrus microbiome (at the OTU level) between Leptocylindrus strains from differing locations along the east coast of Australia, with a higher diversity and more unique OTUs associated with Leptocylindrus strains isolated from the more northern locations compared to those from the south. Furthermore, our data also revealed a Sydney "urban" cluster, where bacterial communities within Leptocylindrus strains originating from sites within this region (Coogee, Clovelly, and Maroubra) differed from strains collected in the more northern sampling locations at Coffs Harbor and Forster, and from the more southern location at Twofold Bay. These differences were attributed to a greater abundance of the Rhodobacteraceae (Roseovarius and Donghicola) within the Leptocylindrus microbiome in strains originating in the Sydney region compared to other locations, whilst the Cryomorphaceae (Owenweeksia) were more abundant members of the Leptocylindrus microbiome in strains originating from Coffs Harbor compared to other locations. While our experimental design is not balanced, that is, it is not easy to disentangle the effect of location and sampling time on the bacterial communities associated with Leptocylindrus strains, our data suggests that different regions and time points harbor distinct bacterial communities.. This may be explained by the fact that different members of the same functional guild may share similar metabolic functions and may therefore populate the same ecological niche in different regions. However, future studies focusing on the conservation of key metabolic elements of these bacteria are needed to support this hypothesis.

While it was outside the scope of our study to examine the evolution of bacterial communities under cultivation over time, Behringer et al. (2018) clearly demonstrated that the microbiome associated with multiple strains of two diatom species remained stable over time. Bacterial communities resampled over approximately 1 year (at 20,200, and 400 days) displayed only small changes in composition. One caveat to their approach, however, was that their diatom microbiomes were characterized 20 days after initial isolation, during which time there may have been changes to the assemblage from the seawater from which they were originally isolated. Our study extends this work by showing that diatom microbiomes do indeed vary from the seawater in which they were isolated yet remain specific to their location of origin under domestication. Moreover, we suggest that a more intensive temporal sampling campaign, including a fully nested factorial experimental design and an examination of the original seawater from which all diatoms are isolated, would further close the gap in our knowledge surrounding the multiscaled, temporal variability of diatom microbiomes from natural assemblages.

\section{Leptocylindrus Core Microbiome}

In order to understand the function of a host organism's microbiome, which may play a critical role in its interaction with the environment, many researchers are beginning to investigating the 'core microbiome' of specific marine taxa (Schmitt et al., 2012; Ainsworth et al., 2015; Bengtsson et al., 2017; Lawson et al., 2018).
Examination of the core microbiome of Leptocylindrus identified only one core OTU, Roseovarius sp. Species belong to Roseovarius are the most predominant microbial taxa documented in the marine algal-bacteria literature (Rappe et al., 2000; Grossart et al., 2005; Guannel et al., 2011; Amin et al., 2012; Ramanan et al., 2016 and references therein). Unsurprisingly, it was the family Rhodobacteraceae (to which Roseovarius sp. belongs) which also characterized $\sim 70-100 \%$ of the core microbiomes belonging to each location. Interestingly however, network analysis revealed that the microbiome across all strains were both spatially and temporally variable, that is, Leptocylindrus strains collected from specific locations and months harbored a unique set of bacterial OTUs (as well as many shared OTUs). A very likely explanation for this variability may be that the local environment (light penetration, water temperature and nutrient availability) may drive community composition.

\section{CONCLUSION}

The diatom genus Leptocylindrus is a dominant component of the phytoplankton community, particularly in coastal upwelling systems around the world. Examination the microbiome of 36 cultivated strains belonging to three species belonging to this genus revealed Roseobacter and Flavobacteria to be the dominant taxa across all species and strains, with a single-taxa core microbiome determined. When the bacterial community was examined across multiple locations and sampling times however, significant spatial and temporal variability amongst strains was observed. Furthermore, while communities under domestication varied from the seawater in which they were isolated, they remained specific to the location/month of origin, that is, different regions and time points harbored distinct bacterial communities. Until now our knowledge of diatom microbiomes has been limited to a few strains/species which have often been sourced from long-term culture collections, with little information or examination of the environment from where they were isolated. Our study delivers new knowledge concerning diatom-bacterial associations, by revealing that the location from which a diatom is isolated plays an important role in shaping its microbiome. A major challenge will be to elucidate the metabolic nature of the relationship between these ecologically relevant partners that incorporates this temporal and spatial variability.

\section{AUTHOR CONTRIBUTIONS}

$\mathrm{PA}, \mathrm{SM}$, and JS are responsible for the conceptualization of this work. PA, TK, NS, and RC performed the analysis. All authors are responsible for the writing, reviewing, and editing of this manuscript.

\section{FUNDING}

This work was funded by the University of Technology Sydney Chancellor's Postdoctoral Fellowship scheme and ARC Discovery Project grants (DP140101045 and DP180100938). 


\section{ACKNOWLEDGMENTS}

PA would like to thank Leo Hardtke for map production and the University of Technology Sydney Chancellor's Postdoctoral Fellowship scheme.

\section{REFERENCES}

Ainsworth, T. D., Krause, L., Bridge, T., Torda, G., Raina, J. B., Zakrzewski, M., et al. (2015). The coral core microbiome identifies rare bacterial taxa as ubiquitous endosymbionts. ISME J. 9, 2261-2274. doi: 10.1038/ismej.2015.39

Ajani, P. A., Armbrecht, L. H., Kersten, O., Kohli, G. S., and Murray, S. A. (2016a). Diversity, temporal distribution and physiology of the centric diatom Leptocylindrus Cleve (Bacillariophyta) from a southern hemisphere upwelling system. Diatom Res. 31, 351-365. doi: 10.1080/0269249X.2016.126 0058

Ajani, P. A., Hallegraeff, G., Allen, D., Coughlan, A., Richardson, A. J., Armand, L., et al. (2016b). Establishing baselines: a review of eighty years of phytoplankton diversity and biomass in southeastern Australia. Oceanogr. Mar. Biol. Annu. Rev. 54, 387-412. doi: 10.1201/9781315368597-9

Ajani, P. A., Allen, A. P., Ingleton, T., and Armand, L. (2014a). A decadal decline in relative abundance and a shift in microphytoplankton composition at a longterm coastal station off southeast Australia. Limnol. Oceanogr. 59, 519-531. doi: 10.4319/lo.2014.59.2.0519

Ajani, P. A., Allen, A. P., Ingleton, T., and Armand, L. (2014b). Erratum: a decadal decline in relative abundance and a shift in phytoplankton composition at a long-term coastal station off southeast Australia. Limnol. Oceanogr. 59, 2240-2242. doi: 10.4319/lo.2014.59.6.2240

Amin, S. A., Hmelo, L. R., van Tol, H. M., Durham, B. P., Carlson, L. T., Heal, K. R., et al. (2015). Interaction and signalling between a cosmopolitan phytoplankton and associated bacteria. Nature 522, 98-101. doi: 10.1038/nature14488

Amin, S. A., Parker, M. S., and Armbrust, E. V. (2012). Interactions between diatoms and bacteria. Microbiol. Mol. Biol. Rev. 76, 667-684. doi: 10.1128/ MMBR.00007-12

Armbrust, E. V. (2009). The life of diatoms in the world's oceans. Nature 459, 185-192. doi: 10.1038/nature 08057

Azam, F., and Ammerman, J. W. (1984). Flows of Energy and Materials in Marine Ecosystems: Theory and Practice, ed. M. J. R. Fasham (Berlin: Springer), 345-360.

Behringer, G., Ochsenkuhn, M. A., Fei, C., Fanning, J., Koester, J. A., and Amin, S. A. (2018). Bacterial communities of diatoms display strong conservation across strains and time. Front. Microbiol. 9:659. doi: 10.3389/fmicb.2018. 00659

Bengtsson, M. M., Buhler, A., Brauer, A., Dahlke, S., Schubert, H., and Blindow, L. (2017). Eelgrass leaf surface microbiomes are locally variable and highly correlated with epibiotic eukaryotes. Front. Microbiol. 8:1312. doi: 10.3389/ fmicb.2017.01312

Bolch, C. J. S., Bejoy, T. A., and Green, D. H. (2017). Bacterial associates modify growth dynamics of the dinoflagellate Gymnodinium catenatum. Front. Microbiol. 8:670. doi: 10.3389/fmicb.2017.00670

Buchan, A., LeCleir, G. R., Gulvik, C. A., and Gonzalez, J. M. (2014). Master recyclers: features and functions of bacteria associated with phytoplankton blooms. Nat. Rev. Microbiol. 12, 686-698. doi: 10.1038/nrmicro 3326

Bunse, C., Bertos-Fortis, M., Sassenhagen, I., Sildever, S., Sjoqvist, C., Godhe, A., et al. (2016). Spatio-temporal interdependence of bacteria and phytoplankton during a Baltic Sea spring bloom. Front. Microbiol. 7:517. doi: 10.3389/fmicb. 2016.00517

Caporaso, J. G., Kuczynski, J., Stombaugh, J., Bittinger, K., Bushman, F. D., Costello, E. K., et al. (2010). QIIME allows analysis of high-throughput community sequencing data. Nat. Methods 7, 335-336. doi: 10.1038/ nmeth.f.303

Cho, D. H., Ramanan, R., Heo, J., Lee, J., Kim, B. H., Oh, H. M., et al. (2015). Enhancing microalgal biomass productivity by engineering a microalgalbacterial community. Bioresour. Technol. 175, 578-585. doi: 10.1016/j.biortech. 2014.10.159

\section{SUPPLEMENTARY MATERIAL}

The Supplementary Material for this article can be found online at: https://www.frontiersin.org/articles/10.3389/fmicb. 2018.02758/full\#supplementary-material

Clarke, K. R., and Gorley, R. N. (2006). PRIMER v5 (\& v6): User Manual/Tutorial. Plymouth: PRIMER-E Ltd.

Clarke, K. R., and Warwick, R. M. (2001). Change in Marine Communities: An Approach to Statistical Analysis and Interpretation, 2nd Edn. Plymouth: PRIMER-E.

Croft, M. T., Lawrence, A. D., Raux-Deery, E., Warren, M. J., and Smith, A. G. (2005). Algae acquire vitamin B12 through a symbiotic relationship with bacteria. Nature 438, 90-93. doi: 10.1038/nature04056

Desbois, A. P., Mearns-Spragg, A., and Smith, V. J. (2009). A fatty acid from the diatom Phaeodactylum tricornutum is antibacterial against diverse bacteria including multi-resistant Staphylococcus aureus (MRSA). Mar. Biotechnol. 11, 45-52. doi: 10.1007/s10126-008-9118-5

Durham, B. P., Dearth, S. P., Sharma, S., Amin, S. A., Smith, C. B., Campagna, S. R., et al. (2017). Recognition cascade and metabolite transfer in a marine bacteria-phytoplankton model system. Environ. Microbiol. 19, 3500-3513. doi: $10.1111 / 1462-2920.13834$

Durham, B. P., Sharma, S., Luo, H., Smith, C. B., Amin, S. A., Bender, S. J., et al. (2015). Cryptic carbon and sulfur cycling between surface ocean plankton. Proc. Natl. Acad. Sci. U.S.A. 112, 453-457. doi: 10.1073/pnas.1413137112

Fawcett, S. E., and Ward, B. B. (2011). Phytoplankton succession and nitrogen utilization during the development of an upwelling bloom. Mar. Ecol. Prog. Ser. 428, 13-31. doi: 10.3354/meps09070

Foster, R. A., Kuypers, M. M., Vagner, T., Paerl, R. W., Musat, N., and Zehr, J. P. (2011). Nitrogen fixation and transfer in open ocean diatom-cyanobacterial symbioses. ISME J. 5, 1484-1493. doi: 10.1038/ismej.2011.26

Gibbons, S. M., Caporaso, J. G., Pirrung, M., Field, D., Knight, R., and Gilbert, J. A. (2013). Evidence for a persistent microbial seed bank throughout the global ocean. Proc. Natl. Acad. Sci. U.S.A. 110, 4651-4655. doi: 10.1073/pnas. 1217767110

Grant, M. A., Kazamia, E., Cicuta, P., and Smith, A. G. (2014). Direct exchange of vitamin B12 is demonstrated by modeling the growth dynamics of algal-bacterial co-cultures. ISME J. 8, 1418-1427. doi: 10.1038/ismej. 2014.9

Green, D. H., Echavarri-Bravo, V., Brennan, D., and Hart, M. C. (2015). Bacterial diversity associated with the coccolithophorid algae Emiliania huxleyi and Coccolithus pelagicus f. braarudii. Biomed. Res. Int. 2015:194540. doi: 10.1155/ 2015/194540

Grossart, H. P., Levold, F., Allgaier, M., Simon, M., and Brinkhoff, T. (2005). Marine diatom species harbor distinct bacterial communities. Environ. Microbiol. 7, 860-873. doi: 10.1111/j.1462-2920.2005.00759.x

Guillard, R. R. L. (1975). "Culture of phytoplankton for feeding marine invertebrates," in Proceedings of the Culture of Marine Invertebrate Animals, eds W. L. Smith and M. H. Chanley (New York, NY: Plenum Press), 26-60.

Guannel, M. L., Horner-Devine, M. C., and Rocap, G. (2011). Bacterial community composition differs with species and toxigenicity of the diatom Pseudo-nitzschia. Aquat. Microb. Ecol. 64, 117-133. doi: 10.3354/ ame01513

Gutierrez, T., Green, D. H., Nichols, P. D., Whitman, W. B., Semple, K. T., and Aitken, M. D. (2013). Polycyclovorans algicola gen. nov., sp. nov., an aromatichydrocarbon-degrading marine bacterium found associated with laboratory cultures of marine phytoplankton. Appl. Environ. Microbiol. 79, 205-214. doi: 10.1128/AEM.02833-12

Hattenrath-Lehmann, T. K., and Gobler, C. J. (2017). Identification of unique microbiomes associated with harmful algal blooms caused by Alexandrium fundyense and Dinophysis acuminata. Harmful Algae 68, 17-30. doi: 10.1016/ j.hal.2017.07.003

Huang, B. Q., Xiang, W. G., Zeng, X. B., Chiang, K. P., Tian, H. J., Hu, J., et al. (2011). Phytoplankton growth and microzooplankton grazing in a subtropical coastal upwelling system in the Taiwan Strait. Continental Shelf Res. 31, S48S56. doi: 10.1016/j.csr.2011.02.005 
Kahlke, T. (2018). Ampli-tools (Version 1.0). Geneva: Zenodo. doi: 10.5281/zenodo. 1137872

Lane, D. J. (1991). "16S/23S rRNA sequencing," in Proceedings of the Nucleic Acid Techniques in Bacterial Systematics, eds E. Stackebrandt and M. Goodfellow (Chichester: John Wiley and Sons), 115-175.

Lau, W. W. Y., Keil, R. G., and Armbrust, E. V. (2007). Succession and diel transcriptional response of the glycolate-utilizing component of the bacterial community during a spring phytoplankton bloom. Appl. Environ. Microbiol. 73, 2440-2450. doi: 10.1128/aem.10965-06

Lawson, C. A., Raina, J. B., Kahlke, T., Seymour, J. R., and Suggett, D. J. (2018). Defining the core microbiome of the symbiotic dinoflagellate, Symbiodinium. Environ. Microbiol. Rep. 10, 7-11. doi: 10.1111/1758-2229.12599

Legendre, L., and Rassoulzadegan, F. (1995). Plankton and nutrient dynamics in marine waters. Ophelia 41, 153-172. doi: 10.1080/00785236.1995.10422042

Magoc, T., and Salzberg, S. L. (2011). FLASH: fast length adjustment of short reads to improve genome assemblies. Bioinformatics 27, 2957-2963. doi: 10.1093/ bioinformatics/btr507

Malviya, S., Scalco, E., Audic, S., Vincent, F., Veluchamy, A., Poulain, J., et al. (2016). Insights into global diatom distribution and diversity in the world's ocean. Proc. Natl. Acad. Sci. U.S.A. 113, E1516-E1525. doi: 10.1073/pnas. 1509523113

Moejes, F., Succurro, A., Popa, O., Maguire, J., and Ebenhöh, O. (2017). Dynamics of the bacterial community associated with Phaeodactylum tricornutum cultures. Processes 5:77. doi: 10.3390/pr5040077

Morales, C. E., and Anabalon, V. (2012). Phytoplankton biomass and microbial abundances during the spring upwelling season in the coastal area off Concepcion, central-southern Chile: variability around a time series station. Prog. Oceanogr. 9, 81-91. doi: 10.1016/j.pocean.2011.07.004

Moran, M. A., González, J. M., and Kiene, R. P. (2003). Linking a bacterial taxon to sulfur cycling in the sea: studies of the marine Roseobacter group. Geomicrobiol. J. 20, 375-388. doi: 10.1080/01490450303901

Muegge, B. D., Kuczynski, J., Knights, D., Clemente, J. C., González, A., Fontana, L., et al. (2011). Diet drives convergence in gut microbiome functions across mammalian phylogeny and within humans. Science 332, 970-974. doi: 10.1126/ science. 1198719

Needham, D. M., Sachdeva, R., and Fuhrman, J. A. (2017). Ecological dynamics and co-occurrence among marine phytoplankton, bacteria and myoviruses shows microdiversity matters. ISME J. 11, 1614-1629. doi: 10.1038/ismej.2017.29

Ramanan, R., Kim, B. H., Cho, D. H., Oh, H. M., and Kim, H. S. (2016). Algaebacteria interactions: evolution, ecology and emerging applications. Biotechnol. Adv. 34, 14-29. doi: 10.1016/j.biotechadv.2015.12.003

Rappe, M. S., Vergin, K., and Giovannoni, S. J. (2000). Phylogenetic comparisons of a coastal bacterioplankton community with its counterparts in open ocean and freshwater systems. FEMS Microbiol. Ecol. 33, 219-232. doi: 10.1016/S01686496(00)00064-7

Richter, L. V., Mansfeldt, C. B., Kuan, M. M., Cesare, A. E., Menefee, S. T., Richardson, R. E., et al. (2018). Altered microbiome leads to significant phenotypic and transcriptomic differences in a lipid accumulating chlorophyte. Environ. Sci. Technol. 52, 6854-6863. doi: 10.1021/acs.est.7b06581

Rognes, T., Flouri, T., Nichols, B., Quince, C., and Mahe, F. (2016). VSEARCH: a versatile open source tool for metagenomics. PeerJ 4:e2584. doi: 10.7717/peerj. 2584
Schafer, H., Abbas, B., Witte, H., and Muyzer, G. (2002). Genetic diversity of 'satellite' bacteria present in cultures of marine diatoms. FEMS Microbiol. Ecol. 42, 25-35. doi: 10.1111/j.1574-6941.2002. tb00992.x

Schloss, P. D., Westcott, S. L., Ryabin, T., Hall, J. R., Hartmann, M., Hollister, E. B., et al. (2009). Introducing mothur: open-source, platform-independent, community-supported software for describing and comparing microbial communities. Appl. Environ. Microbiol. 75, 7537-7541. doi: 10.1128/AEM. 01541-09

Schmitt, S., Tsai, P., Bell, J., Fromont, J., Ilan, M., Lindquist, N., et al. (2012). Assessing the complex sponge microbiota: core, variable and species-specific bacterial communities in marine sponges. ISME J. 6, 564-576. doi: 10.1038/ ismej.2011.116

Segev, E., Wyche, T. P., Kim, K. H., Petersen, J., Ellebrandt, C., Vlamakis, H., et al. (2016). Dynamic metabolic exchange governs a marine algal-bacterial interaction. eLife 5:e17473. doi: 10.7554/eLife.17473

Seymour, J. R., Amin, S. A., Raina, J. B., and Stocker, R. (2017). Zooming in on the phycosphere: the ecological interface for phytoplankton-bacteria relationships. Na. Microbiol. 2:17065. doi: 10.1038/nmicrobiol.2017.65

Shannon, P., Markiel, A., Ozier, O., Baliga, N. S., Wang, J. T., Ramage, D., et al. (2003). Cytoscape: a software environment for integrated models of biomolecular interaction networks. Genome Res. 13, 2498-2504. doi: 10.1101/ gr.1239303

Sison-Mangus, M. P., Jiang, S., Tran, K. N., and Kudela, R. M. (2014). Host-specific adaptation governs the interaction of the marine diatom, Pseudo-nitzschia and their microbiota. ISME J. 8, 63-76. doi: 10.1038/ismej. 2013.138

Song, L. (2017). A multiomics approach to study the microbiome response to phytoplankton blooms. Appl. Microbiol. Biotechnol. 101, 4863-4870. doi: 10. 1007/s00253-017-8330-5

Teeling, H., Fuchs, B. M., Bennke, C. M., Kruger, K., Chafee, M., Kappelmann, L., et al. (2016). Recurring patterns in bacterioplankton dynamics during coastal spring algae blooms. eLife 5:e11888. doi: 10.7554/eLife.11888

Turner, S., Pryer, K. M., Miao, V. P., and Palmer, J. D. (1999). Investigating deep phylogenetic relationships among cyanobacteria and plastids by small subunit rRNA sequence analysis1. J. Eukaryot. Microbiol. 46, 327-338. doi: 10.1111/j. 1550-7408.1999.tb04612.x

van Tol, H. M., Amin, S. A., and Armbrust, E. V. (2017). Ubiquitous marine bacterium inhibits diatom cell division. ISME J. 11, 31-42. doi: 10.1038/ismej. 2016.112

Conflict of Interest Statement: The authors declare that the research was conducted in the absence of any commercial or financial relationships that could be construed as a potential conflict of interest.

Copyright (c) 2018 Ajani, Kahlke, Siboni, Carney, Murray and Seymour. This is an open-access article distributed under the terms of the Creative Commons Attribution License (CC BY). The use, distribution or reproduction in other forums is permitted, provided the original author(s) and the copyright owner(s) are credited and that the original publication in this journal is cited, in accordance with accepted academic practice. No use, distribution or reproduction is permitted which does not comply with these terms. 